\title{
Study on Optimization of Macro Economics Teaching Effect Based on the Evaluation of Classroom Teaching Quality
}

\author{
Chunyan Jiang ${ }^{\mathrm{a}},{\text { Xiaoyan } \mathrm{Wu}^{\mathrm{b}} \text { and Ping Guo }}^{\mathrm{c}}$ \\ School of economy and management, Shijiazhuang TieDao University, Shijiazhuang 050043, China \\ ajiangchunyan0525@163.com, bqibabi@163.com, cguo-gp@sina.com
}

\begin{abstract}
As the basic course of economy and management, the content of macroeconomics course is abstract, and it involves a wide range of knowledge, and the effect of classroom teaching quality evaluation is not satisfactory. There are a lot of problems in the course teaching, for example, it is difficult to apply in practice, teaching reform is difficult to continue to attract students interest, assessment methods is outdated. Not clear about the purpose of learning, the unfamiliar with macroeconomic operation and the lack of interest in macroeconomics led to the above problems. Therefore, the introduction of real-time multimedia data, seize the interest of students, the development of situation case teaching, the reform of traditional assessment methods can be used to stimulate student interest, clear learning objective and strive for a better teaching effect.
\end{abstract}

Keywords: Macroeconomics; Evaluation of classroom teaching quality; interest; assessment methods.

\section{基于课堂教学质量评价的宏观经济学教学效果优化研究}

\author{
蒋春艳, 吴晓艳, 郭平 \\ 石家庄铁道大学, 石家庄 中国
}

摘 要: 作为经济管理类专业的基础课, 宏观经济学课程内容抽象, 涉及知识面较为宽泛, 课 堂教学质量评价效果不尽如人意, 存在理论难以运用于日常生活实践、教学改革难以持续吸 引学生兴趣、考核手段保守等问题, 究其原因, 在很大程度上是由于学生对宏观经济学不感 兴趣, 学习目的不明确, 不熟悉宏观经济运行情况, 因此, 可以考虑引入实时多媒体视频资 料、抓住学生的兴趣点、开展情境案例教学、改革传统考核方式等多手段配合, 激发学生的 兴趣, 明确学习目的, 争取更好的教学效果。

关键词: 宏观经济学; 课堂教学质量评价; 兴趣; 考核方法

\section{1. 前言}

作为经济管理类专业的基础性课程, 各大高校都开设了宏观经济学的必修课、学位课和选修 课, 周课时 2-4 节, 学分 2-3 分不等, 多选择人大出版社高鸿业的《西方经济学》作为教材, 课程内容偏重理论, 涵盖了国民收入核算、简单国民收入决定、IS-LM 模型、宏观经济政策 及其分析、失业与通胀 经济增长与经济周期、开放条件下的宏观经济政策等内容。作为专 业基础课程, 可以帮助学生利用经济学原理去研究市场运行和发展的规律, 加深对社会经济 问题的理解, 但是由于偏重理论和模型分析, 研究对象比较抽象, 因此, 如何提高该门课程 的教学质量备受关注。从前人研究成果来看, 王鹏飞 (2010) 指出在理论性较强的西经课程 中适当的运用案例教学, 有利于提高学生的经济敏感度, 培养学生的宏观分析能力。何治国 （2010）在分析地方工科院校特点基础上, 提出利用数学工具、理论内容适当取舍、注重于 学生的教学互动等方面提出了提高教学效果的途径。康爱香 (2013) 以宏观经济学课程特点 为基础, 提出兴趣是开启宏观经济学大门的钥匙, 可以通过转变教学方式、学生思维方式等 措施来提高课堂教学效果。 
本研究立足大学课堂教学质量评价数据, 通过分析课堂教学中存在的问题和原因, 探究优化 宏观经济学课程教学效果的对策, 对于提高宏观经济学的效果、应对日趋严峻的就业形势具 有重要的现实意义。

\section{2. 宏观经济学课堂教学存在的问题、原因和对策分析}

2.1. 宏观经济学课堂教学存在的问题

目前, 为培养符合社会需要的人才, 提高课堂教学质量, 各高校都要求学生在学期末对教师 授课效果进行评价, 作为专业基础课, 西方经济学课程教学评价结果不尽如人意。从学生对 教师的课堂教学评价数据来看, 目前宏观经济学课堂教学主要存在如下问题:

2.1.1宏观经济学理论难以运用于日常生活实践

作为理论性较强的课程, 如果不能与实践相结合, 学生只能是学过理论, 很难真正将理论运 用于社会实践。与贴近生活的微观经济学理论相比, 宏观经济学理论看不见摸不着, 学生很 难利用生活中的案例来加深对宏观经济理论的理解, 比如国民收入核算、经济增长、居民消 费、投资、经济周期、财政政策、货币政策等问题覆盖面广, 对于大一大二的学生来说, 没 有足够的社会实践来理解这些现象, 更别提居于这些经济现象背后的经济规律了。此外, 研 究宏观经济运行状况, 主要借助如GDP、CPI、失业率等关键指标, 而这些指标距离学生的生 活过于遥远, 学生可以搜集新的GDP、CPI和失业的数据, 但是很难将理论应用于现实生活, 看不到指标的变化对其日常生活的影响。

2.1.2教学方法改革手段频出, 但难以持续吸引学生兴趣

近年来各大高校都日益重视课堂教学质量评价, 鼓励教师积极进行课堂教学改革, 案例分析 法、参与式教学法、情景模拟教学法、沙盘模拟等都被引入到宏观经济学课程教学, 但是或 者由于案例内容过时, 以陈年旧事为主, 或者没有设计很好的切入点去吸引学生的兴趣, 导 致在教学改革过程中, 学生用脚投票的居多, 不愿意参与其中。

2.1.3课程考核方法偏保守, 难以突出培养学生能力

目前宏观经济学考核方式以考试为主, 虽然高校增加了过程考核的内容, 要求教师在期末成 绩中考虑学生的平时成绩, 但是占比不高, 以 $20 \%-30 \%$ 居多, 而期末考试试卷题目以单选、多 选、填空、简答、计算为主, 案例分析、论述等发挥性题目较少, 对学生而言, 只要在考试 前好好背理论内容就可以取得较好的成绩, 没有进一步探究理论实践应用的动力。

2.2. 原因分析

2.2.2学生对宏观经济学不感兴趣

兴趣是最好的老师, 培养学生学习的兴趣, 能够充分发挥其主观能动性, 使之积极主动地进 行学习。目前宏观经济学课堂教学效果不理想, 在很大程度上源于学生对该门课程不感兴趣, 教师在课堂教学改革中所做的努力, 在很多情况下, 都是因为没有抓住学生的兴趣点去展开 实践, 而出现事倍功半的效果。

2.2.2学生学习目的不明确

虽然已经进入大学阶段, 就业形势严峻的大背景之下, 依然存在很多学生学习目的不明确, 为了学分、毕业、考研而学的大有人在, 导致学生学习理论浅尝轩止, 没有动力进一步探究 理论的实践应用。

2.2.3学生没有接触宏观经济实践的机会

直于年龄和校规的限制, 学生没有过多的机会接触社会实践, 很难形成对各种宏观经济现象 的明确认知, 造成了对宏观经济理论模型所提及的各种要素对国民收入决定的影响机制很难 有深入的理解，更别提把理论应用于实践。

2.3. 宏观经济学课堂教学效果优化对策

作为一线任课教师, 直接面对学生, 可以从教学方法、教学内容、教学手段和考核方法等多 方面去实践, 以达到令教与学双方都能接受的、更好的教学效果。 


\section{3. 1 引入实时视频资料, 帮助学生了解社会经济实践}

现在高校几乎所有的教学楼都可以使用多媒体, 教师在授课过程中可以利用各种多媒体资源 来帮助学生了解和熟悉宏观经济运行情况。课上时间有限, 可以考虑利用课间和课后时间让 学生去观看大量的视频资料片, 比如第一时间、经济半小时、央视财经评论等实时的财经评 论节目, 让学生能了解宏观经济领域出现了什么变化, 如何结合理论去解决这些新的问题, 政府目前实施的宏观经济政策对我们的生活会有什么影响, 我们又该做何种抉择, 真正做到 学以致用。当然, 要做到这些, 需要在课前做大量工作, 除了熟悉课程内容之外, 还要利用 各种视频下载工具如稞麦、维棠、硕鼠等, 从网上寻找与课程内容契合度高的视频资源, 最 好是实事视频资料, 让学生了解象牙塔之外正在发生着什么, 然后根据视频资源的内容设计 问题, 让学生能结合理论去解决问题。

2.3.2 明确学习目的, 抓住学生的兴趣点, 借题发挥

任何课程都是依据专业发展的需要而开设, 但是学生可能并不了解他所要学习的课程对自己 的将来有何用途, 因此, 需要教师在授课伊始就加以引导, 让学生明确知道这门课程对自己 现在和将来的发展有何用途。宏观经济学课程的第一节课非常关键, 因为教师需要在这一节 课中让学生对课程产生兴趣, 帮助学生明确学习目的, 否则后边的内容难以展开。要做到这 点, 需要结合学生的专业、知识背景、家庭背景、学习态度和学习动机等多方面因素。讲授 宏观经济学时, 不是站在国家政府的角度, 而是站在个人的角度去告诉学生政府的宏观经济 政策变动对其生活的影响, 对将来就业的影响, 对其专业发展的影响, 学生更容易理解和接 受。讲授GDP的核算方法时, 让学生去调研发生在身边的事情对GDP会产生什么影响。在调研 过程中, 学生经常有拿不准的情况, 自己会主动去翻书或上网查资料, 在课上展示的时候能 娓娓道来。通过上述方法抓住学生的兴趣点, 在课程内容中借题发挥, 真正让学生明了课程 对他的意义, 变被动的 “要我学” 为 “我要学”, 事半功倍。

2.3.3提高学生对课程内容的参与度, 翻转课堂

抓住学生一时的兴趣容易, 难的是32课时或48课时都把学生的积极性调动起来, 让学生对课 程的兴趣从第一周持续到第十六周。在授课过程中, 可以考虑改变传统的教师讲、学生听的 模式, 翻转课堂, 让学生成为主体: 教师可以创设某一情境, 设置问题让学生自己去解决, 提高学生对课程内容的参与度。比如讲授宏观经济政策时, 如果正好赶上美国总统大选, 设 置情境如果你是候选人, 在宏观经济政策方面, 你会倾向于向你的选民作出什么样的承诺或 竞选宣言。这种情境案例教学的展开离不开教师的指导, 一旦学生的模拟演练, 偏离了讨论 的主题, 教师要适时干预, 避免课时的浪费。

2. 3. 4 教学方法革新需考核方法创新的配合

教学方法手段的革新离不开考核方法的创新, 仅凭期末考试成绩是无法准确衡量学生对课程 内容的理解程度的, 因此, 在期末考核上加大过程考核力度, 学生平时成绩占比至少要提高 到 $50 \%$ 以上, 平时成绩高低以学生对课堂教学内容参与程度来评判。同时, 在期末试卷中加大 案例分析性题目的比重, 切实了解学生对课程内容的理解程度。

\section{3. 结论}

本研究提出的优化宏观经济学教学效果的举措旨在激发学生的学习兴趣, 帮助学生明确学习 目的, 提高对课程内容的参与度, 让学生真正成为学习的主体, 这样教学效果才能事半功倍。 兴趣是最好的老师, 能不能引起学生对课程的兴趣关键在授课教师身上, 三尺讲台是我们最 好的演武场。未来教学改革之路漫漫, 吾辈当上下而求索。

\section{References}

[1] Wang Peng-fei. Case Teaching in Western Economics Teaching. JOURNAL OF GUANGXI NORMAL UNIVERSITY FOR NATIONALITIES. Vol.27 (2010) NO.2, p.114-116. 
[2] He Zhi-guo. The Research of Promotion Teaching of Western Economics in Local Engineering Colleges. SCIENCE and TECHNOLOGY INFORMATION. Vol.15(2010)No.15,p.133

[3] Kang Ai-xiang. Research on Improving the Teaching Effect of Macroeconomics-Interest is the Key of Macroeconomics. Vol.16(2013)No.2,p.14-18 